\title{
Full composition range silicon oxynitride films deposited by ECR-PECVD at room temperature
}

\author{
A. del Prado ${ }^{a, *}$, I. Mártiı ${ }^{a}$, M. Fernández ${ }^{b}$, G. González-Díaz ${ }^{a}$ \\ ${ }^{\star}$ Dpto. Fisica Aplicada II, Focultad Ciencias Fistcas, Universidad Complutense de Madrid, Avenida Complutense SN, 28040 Madrid, Spain \\ "Insituto de Ciencia de Materiales, 28049 Cantoblanco, Spain
}

\begin{abstract}
Silicon oxynitride films were deposited at room temperature using the ECR-PECVD techniquc. Precursor gases were $\mathrm{O}_{2}, \mathrm{~N}_{2}$ and $\mathrm{SiH}_{4}$. The composition of the films can be controlled by regulating the gases flow ratio. $R=\left(\mathrm{O}_{2}+\mathrm{N}_{2}\right) / \mathrm{SiH}_{4}$ and $R^{\prime}=\mathrm{O}_{2} / \mathrm{SiH}_{4}$ have proved to be the key deposition parameters. FTIR spectroscopy, AES and elipsometric measurements were performed in order to characterise the films. $A$ single $\mathrm{Si}-\mathrm{O} / \mathrm{Si}-\mathrm{N}$ stretching band is observed in the FTIR spectrum for all compositions, indicating single-phase homogeneous $\mathrm{SiO}_{x} \mathrm{~N}_{\mathrm{y}}$ films. FWHM of the stretching band shows a maximum for the composition comesponding to the same aumber of Si-O and Si-N bonds. Samples cover the whole composition range from silicon nitride to silicon oxide including nitrogen-rich films, even though the gas flow ratio $R^{7}=$ $\mathrm{N}_{2} / \mathrm{O}_{2}$ during deposition was small (from $R^{\prime \prime}=1.0$ for $\mathrm{SiO}_{1,5 \mathrm{~N}_{0,04}}$ to $R^{\prime \prime}=6.7$ for $\mathrm{SiO}_{0.26} \mathrm{~N}_{12}$ ). Silicon oxide composition samples ( $\mathrm{SiO} 20$ ) show essentially the same IR features as the thermal oxide: Si-O stretching band located at $1072 \mathrm{~cm}^{-1}$, with a FWHM of $96 \mathrm{~cm}^{-i}$ and a shoulder/peak ratio of 0.30 , while nitrogen-rich samples $\left(\mathrm{SiO}_{0,25} \mathrm{~N}_{12}\right)$ show a total bonded hydrogen content below $2 \times 10^{22} \mathrm{~cm}{ }^{-3}, 01999$ Elsevier Science S.A. All rights reserved.
\end{abstract}

Keywords: Silicon oxynitride; Plasma processing and deposition; Fourier transform infrared spectroscopy

\section{Introduction}

Silicon oxynitride arises as a very attractive material in the microelectronic industry as it shows some advantages with respect to $\mathrm{SiO}_{2}$ (lower permeability to boron-atom diffusion and alkali ions, better reliability of the devices and higher dielectric constant [1]), and $\mathrm{Si}_{3} \mathrm{~N}_{4}$ (lower mechanical stress and a higher band gap [2]).

Different techniques are available for the deposition of $\mathrm{SiO}_{x} \mathrm{~N}_{y}$ films. The electron cyclotron resonance method (ECR-CVD) is very promising, as it is a low thermal budget process, allows a very high activation of the precursor gases, and the substrate is placed outside the plasma chamber, free from ion bombardment.

In this paper we present the results obtained for $\mathrm{SiO}_{x} \mathrm{~N}_{y}$ films deposited on Si substrates at room temperature using the ECR-CVD technique.

\section{Experiment}

The films were deposited using an Astex ECR plasma

* Corresponding author. Tel.: + 34-91-3944434; fax: + 34-913945196.

E-mail address: alvarop(0)ewax.sim,umies (A. del Prado) source model $\mathrm{AX} 4500$, attached to an in-house design deposition chamber [3]. Precursor gases were $\mathrm{O}_{2}, \mathrm{~N}_{2}$ (which were fed in the plasma chamber) and $\mathrm{SiH}_{4}$. (which was introduced through a dispersal ring outside the plasma region). Total gas flow, deposition pressure and plasma power were kept constant at $10.52 \mathrm{sccm}, 0.7 \mathrm{mTorr}$ and $100 \mathrm{~W}$, respectively. Three different series of samples were deposited keeping the parameter $R=\left(\mathrm{O}_{2}+\right.$ $\left.\mathrm{N}_{2}\right) / \mathrm{SiH}_{4}$ constant. $(R=1.6, R=5.0$ and $R=9.1$ for series $A, B$ and $C$, respectively). Silicon nitride films deposited under these $R$ values are known to range from near stoichiometric films ( $R=1.6$ ) to nitrogen-rich ones $(R>7.5$ ) [4]. For each series $R^{\prime}=\mathrm{O}_{2} / \mathrm{SiH}_{4}$ was varied between 0 and 4.5 allowing the control of composition from silicon nitride to silicon oxide. Additionally, a series keeping $R^{\prime}=0.8$ constant and varying $R$ from 1.6 to 10.7 was performed. The substrate temperature never rose above $50^{\circ} \mathrm{C}$. The infiuence of plasma power and deposition pressure has been studied in a previous work [5].

High resistivity p-type Si(111) substrates polished on both sides were used in all the depositions. Substrates were chemically cleaned using standard procedures [4]. The thickness of the fims was about $300 \mathrm{~nm}$ for Fourier transform infrared spectroscopy (FTIR) and $100 \mathrm{~nm}$ for composition and ellipsometry measurements. 
Table 1

Deposition condicions and characteristics of some representative samples

\begin{tabular}{|c|c|c|c|c|c|c|}
\hline Sample & $R=\left(\mathrm{O}_{2}-\mathrm{N}_{2}\right) / \mathrm{SiH}_{4}$ & $R^{i}=\mathrm{O}_{2} / \mathrm{SiH}_{+}$ & IR peak wavenumber $\left(\mathrm{cm}^{-1}\right)$ & $x$ in $\mathrm{SiO}, \mathrm{N}$ & $y$ in $\mathrm{SiO}_{1} \mathrm{~N}$ & {$[\mathrm{H}] \times 10^{22} \mathrm{~cm}^{-1}$} \\
\hline$A 1$ & 1.6 & 0.21 & 856 & 0.26 & 1.2 & 2.0 \\
\hline .22 & 1.6 & 0.53 & 911 & 0.66 & 0.81 & 1.6 \\
\hline $\mathrm{Cl}$ & 9.1 & 0.69 & 911 & 0.64 & 0.77 & 1.8 \\
\hline $\mathrm{C}^{2}$ & 9.1 & 1.04 & 972 & 1.2 & 0.63 & 0.9 \\
\hline$C 3$ & 9.1 & 4.5 & 1072 & 2.0 & 0.0 & - \\
\hline
\end{tabular}

FTIR characterisation was performed using a Nicolet 5PC spectrometer operating in the mid-infrared region $(400-$ $4000 \mathrm{~cm}^{-1}$ ). Bonded hydrogen content was determined from the FTIR spectrum using the method developed by Lanford and Rand [6].

Auger electron spectroscopy (AES) measurements were carried out in a JEOL system (JAMP-10S), with a $5 \mathrm{keV}$ electron beam $10.1 \mathrm{~mm}$ diameter) at normal incidence. Samples were bombarded with $2 \mathrm{keV} \mathrm{Ar}^{-}$ions in order to reach the bulk of the film.

The refractive index was obtained from ellipsometric analysis.

\section{Results and discussion}

The FTIR spectrum of the films shows a dominant single phase $\mathrm{Si}-\mathrm{O} / \mathrm{Si}-\mathrm{N}$ stretching band. with the maximum located between 850 and $1072 \mathrm{~cm}^{-1}$. depending on composition.

Table 1 shows the deposition conditions and characteristics of some representative samples. Results for series B and $C$ are analogous. The wavenumber of the main FTIR absorption peak is clearly correlated to the composition of the films. Good agreement in the composition values is reached for samples with the same peak wavenumber deposited under different gas flow ratios.

According to the $\mathrm{AES}$ measurements, near stoichiometric silicon oxynitride films are obtained. Stoichiometric films

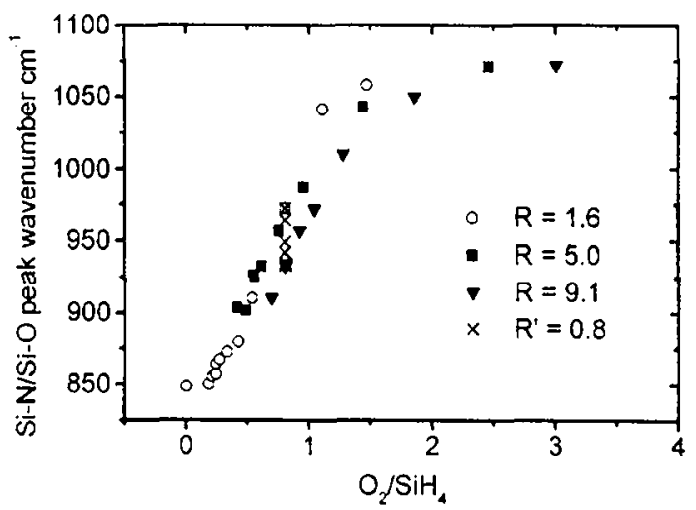

Figr. 1. Wavenumber of the FTIR Si-O/Si-N stretching peak versus the oxvgen to silane ratio for the differem series. $\left(R=\mathrm{N}_{2}+\mathrm{O}_{2} \mathrm{v} / \mathrm{SiH}_{4}\right.$ : $R^{i}=\mathrm{O}_{2} / \mathrm{SiH}_{2}$. are defined according to the relation $x / 2+3 y / 4=1$ [7]. All samples in Table 1 show $x / 2+3 y / 4$ values around 1 , with some dispersion above and below this value.

Fig. I shows the wavenumber of the main absorption band of the FTIR spectrum (Si-O/Si-N stretching) as a function of the $\mathrm{O}_{2} / \mathrm{SiH}$. ratio. The position of the maximum ranges from about $850 \mathrm{~cm}^{-1}$ for silicon nitride to $1072 \mathrm{~cm}^{-!}$ for silicon oxide. covering all intermediate positions. The parameter which mainly determines the position of the maximum (and therefore composition) is $R^{\prime}=\mathrm{O}_{2} / \mathrm{SiH}_{4}$ rather than $R^{\prime \prime}=\mathrm{O}_{2} / \mathrm{N}_{2}$. There is a second order dependence on the parameter $R$, as it can be observed in the results for the $R^{\prime}=0.8$ series. This behaviour is derived from the much higher reactivity of $\mathrm{O}_{2}$ with respect to $\mathrm{N}_{2}$. During the deposition process, reactions to incorporate oxygen and nitrogen to the film are competitive. and the oxygen reaction takes preference. For high values of $R^{\prime}=\mathrm{O}_{2} / \mathrm{SiH}_{4}$, $\left(R^{\prime}>2.5\right)$. all the silane reacts with the $\mathrm{O}_{2}$, despite the presence of $N_{2}$ in the plasma and $\mathrm{SiO}_{2.11}$ composition is obtained. This is a saturation point and higher values of $R^{\prime}$ do not have any further effect in the position of the peak or composition. However, for lower $\mathrm{O}_{2} / \mathrm{SiH}_{4}$ ratio values, there is remaining $\mathrm{SiH}_{4}$ to react with nitrogen, and oxynitride intermediate compositions are obtained.

In the $R^{\prime}=0.8$ series a shift of the peak from 972 to 935 $\mathrm{cm}^{-:}$is observed when $R$ ranges from 1.6 to 10.7. Lucreasing $R$ while keeping $R^{\prime}=\mathrm{O}_{2} / \mathrm{SiH}_{4}$ and total flow constant means to increase the $\mathrm{V}_{2} / \mathrm{SiH}_{4}$ ratio and this increase

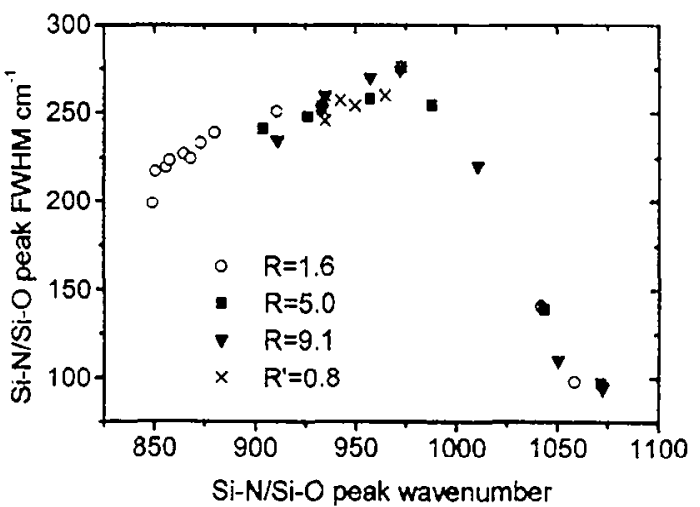

Fig. 2. FWHM of the FTIR Si-O/Si-N strecthing peak versus the wavenumber of the maximuin for the different series. $I R=\mathrm{N}_{2}+\mathrm{O}_{2} V / \mathrm{SiH}_{4}$ : $R^{\prime}=0_{2} / \mathrm{SiH}_{\downarrow}$ ). 


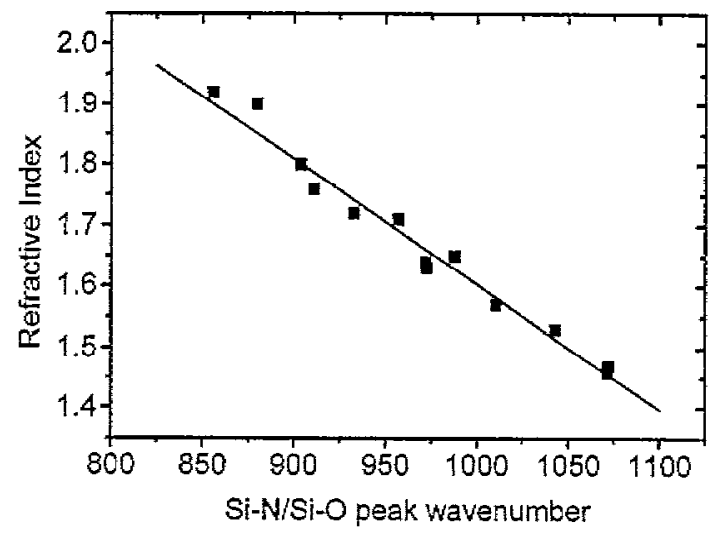

Fig. 3. Refractive index of the films versus the wavenumber of the FTIR $\mathrm{Si}-\mathrm{O} / \mathrm{Si}-\mathrm{N}$ strctching pcak. Solid line corresponds to conventional regression analysis.

enhances the nitrogen incorporation reaction with respect to the oxygen one, and films show more nitride-like features (a shift of the main FTIR peak to lower wavenumbers). In conclusion, oxygen incorporation is primarily determined by the $\mathrm{O}_{2} / \mathrm{SiH}_{4}$ ratio, while the $\mathrm{N}_{2} / \mathrm{SiH}_{4}$ ratio has a second order effect.

Fig. 2 shows the full width at half maximum (FWHM) of the stretching band as a function of the wavenumber of the maximum. The characteristic behaviour for homogeneous samples is observed [8]. When oxygen is incorporated to the films (the wavenumber increases), FWHM increases from about $200 \mathrm{~cm}^{-1}$ for the nitride samples, until a maximum value of $276 \mathrm{~cm}^{-1}$ is reached for wavenumbers around 970 $\mathrm{cm}^{-1}$. The corresponding composition is $\mathrm{SiO}_{1.1} \mathrm{~N}_{0.64}$, which means roughly the same number of $\mathrm{Si}-\mathrm{O}$ and $\mathrm{Si}-\mathrm{N}$ bonds (53\% and $47 \%$, respectively). From this point, FWHM decreases until reaching a value of $96 \mathrm{~cm}^{-1}$ for silicon oxide samples ( $\mathrm{SiO}_{2,1}$ ). FWHM depends on the dispersion of the oscillating frequency of the bonds, which in turn depends on the structural disorcer of the film and the presence of different locai bonding environments [8]. Higher disorder and a higher variety of local environments mean a higher dispersion of the frequency, and thus a higher value of the FWHM. When oxygen is incorporated to the samples, disorder increases and the probability of local environments containing oxygen atoms also increases. If we assume a simplified tetrahedron model without taking into account hydrogen incorporation or silicon content above the stoichiometric value, the probability of a given tetrahedron of the type $\mathrm{Si}-\mathrm{O}_{n}-\mathrm{N}_{4-n}$, for a film of composition $\mathrm{SiO}_{3} \mathrm{~N}_{4}$, is proportional to the factor $P=(x / 2)^{n}(3 y / 4)^{4-n}$. This $P$ factor is maximum for a composition $x / 2=3 y / 4=0.5$. If this condition is achieved, the dispersion of the distribution of the probability of the different tetrahedrons, (or different local environments), is maximum and so is the dispersion of the oscillating frequency and thus the FWHM. The composition condition $x / 2=3 y / 4=0.5$ means the same number of $\mathrm{Si}-\mathrm{O}$ and $\mathrm{Si}-\mathrm{N}$ bonds, which is in good agreement with the experimental result.

Fig. 3 shows refractive index of the films as a function of the main FTIR peak wavenumber. As expected for homogeneous films, refractive index ranges continuously from 1.98 to 1.46 as conposition changes from silicon nitride to silicon oxide. Tutal bunded hydrogen content is shown in Table 1. Samples of series A show both $\mathrm{N}-\mathrm{H}$ and $\mathrm{Si}-\mathrm{H}$ bonds, although the concentration of $\mathrm{N}-\mathrm{H}$ bonds is about two or four times that of $\mathrm{Si}-\mathrm{H}$ bonds depending on composition. For series $B$ and $C,(R=5.0, R=9.1)$, in which the $\mathrm{SiH}_{4}$ partial pressure during deposition is lower, only $\mathrm{N}-\mathrm{H}$ bonds are present. We conclude that the films obtained are near stoichiometric or nitrogen-rich, as it was expected from the results obtained for silicon nitrides [4]. This conclusion is further supported by the refractive index measurements (Fig. 3), [9]. No $\mathrm{O}-\mathrm{H}$ bonds are present in any sample, When oxygen content is increased, total hydrogen content is reduced and both the $\mathrm{Si}-\mathrm{H}$ band and the $\mathrm{N}-\mathrm{H}$ band shift to higher wavenumbers. The $\mathrm{N}-\mathrm{H}$ bond concentration decreases because $\mathrm{N}$ concentration decreases, while $\mathrm{Si}-\mathrm{H}$ bond concentration is reduced due to a substitution of $\mathrm{Si}-\mathrm{H}$ bonds by $\mathrm{Si}-\mathrm{O}$ bonds.

The total bonded $H$ content for the most nitride-like sample is $2 \times 10^{22} \mathrm{~cm}^{-3}$, which is a low value keeping in mind that no substrate heating nor any postdeposition annealing has been carried out.

This low value of the hydrogen content and the FTIR features of the films (single stretching band proving single phase oxynitride, and oxide composition samples with features similar to those obtained for thermal oxides: stretching peak located at $1072 \mathrm{~cm}^{-1}$ with a FWHM of 96 $\mathrm{cm}^{-1}$ and a shoulder/peak ratio of 0.3 ), seem very promising for the potential application of these films to MIS devices after further treatment. Fabrication of MIS devices using silicon nitride and silicon oxide as gate dielectric has already been successfully achieved [10]. Future work will be devoted to the improvement of the quality of these silicon oxynitride films by increasing substrate temperature and performing postdeposition annealing treatments which have been reported to further improve the quality of the films $[1,11]$.

\section{Conclusions}

Single-phase homogeneous silicon oxynitride films have been deposited by ECR-CVD at room temperature. The FTIR spectrum shows a single absotption band which shifts from the silicon nitride to the silicon oxide wavenumber. The FWHM behaves as expected for homogeneous films, showing a maximum for the middle composition between silicon oxide and silicon nitride. Results from the $\mathrm{Si}-\mathrm{H}$ and $\mathrm{N}-\mathrm{H}$ bond concentration, $\mathrm{AES}$ and refractive index indicate that the films obtained are near stoichiometric or nitrogenrich. 
Composition and refractive index can be controlled by changing the precursor gas flow ratios. $R=\mathrm{CO}_{2}+$ $\left.\mathrm{N}_{2}\right) / \mathrm{SiH}_{4}$ and $R^{\prime}=\mathrm{O}_{2} / \mathrm{SiH}_{4}$ are the parameters which mainly determine the properties of the films.

The whole composition range from silicon nitride to silicon oxide is covered. with low values of the $\mathrm{N}_{2} / \mathrm{O}_{2}$ ratio.

Low hydrogen content is observed in the films. despite the fact that no heating of the substrate nor any postdeposition annealing has been performed.

The FTIR characteristics of the silicon oxide samples are close to the thermal oxide values: main peak located at 1072 $\mathrm{cm}^{-}$, with a FWHM of $96 \mathrm{~cm}^{-1}$ and a shoulder/peak ratio of 0.3 .

\section{References}

[1] S.V. Hattangady, H. Niimi, G. Lucorsky, J. Vac. Sci. Technol. A 14 (6) (1996) 3017
[2] J.-I. Yeh, S.-C. Lee, J. Appl. Phys. 79 (2) (1996) 656

[3] S. Garcia. J.M. Martin. M. Fernande\%, I. Martil. G. Gonzalez-Diaz. Phil. Mag. B 73 (3) (1996) 487.

[4] F.L. Martinez, I. Martil. G. Gonzalez-Diaz, B. Selle. I. Sieber. J. NonCryst. Solids 227.230 (1998) 523.

[5] S. Garcia. J.M. Martin, I. Martil. G. Gonzalez-Diaz, Thin Solid Fitms $315(1998) 22$

[6] W.A. Lanford. M.J. Rand, J. Appl. Phys 49 (4) (1978) 2473.

[7] L. N. He. T. Inokuma, S. Hasegawa, Jpn. J. Appl. Phys. 35 (1996) 1503.

[8] D.V. Tsu, G. Lucorsky, M.J. Manini, S.S. Chuo. J. Vac. Sci. Technol. A 5 (4) (1987) 1998.

[9] P.V. Bulkin. P.L. Swart, B.M. Lacquet, J. Non-Cryst. Solids 187 (1995) 484

[10] S. Garcia. J.M. Martin. I. Martil. G. Gonzalez-Diaz, Thin Solid Films 317 (1998) I16.

[11] Y. Ma. G. Lucorsky, J. Vac. Sci. Technol. B 12 (4) (1994) 2504 